\title{
Introduction to the Research Handbook on Big Data Law
}

\author{
Roland Vogl
}

In this era of big data, a wealth of works addresses big data analytics, tools, and techniques, and their societal impacts. It is truly an interdisciplinary dialog, with more voices joining every day. This research handbook represents a scholarly, state-of-the-art overview of research and the scope of current thinking in the field of big data analytics and the law. It is for scholars, practitioners, and students from a variety of related disciplines who wish to survey the issues surrounding big data analytics in legal settings, as well as legal issues surrounding the application of big data techniques in different domains.

\section{WHAT IS BIG DATA LAW?}

From the perspective of legal informatics researchers, big data law is the branch of computational law that concerns itself with data-driven approaches to legal analysis. For legal scholars, big data law is the field of empirical legal scholarship that leverages big data analyticsspecifically, advances in statistical artificial intelligence, including machine learning, natural language processing, and deep learning - to identify patterns in legal information, to draw conclusions, to make policy recommendations, and to predict legal outcomes. Outside the academy, legal practitioners use big data law tools to discover the "smoking gun" evidence in litigation, to conduct due diligence, predict judicial or legislative outcomes, and automate certain legal processes. Innovative legal tech entrepreneurs see big data law as a relatively wide-open field of opportunity for building and commercializing products that leverage specialized analytics for legal use cases. While these stakeholders may assign slightly different meanings to big data law, the insights and capabilities gained through applying big data analytics in law share a complexity, scale, and depth very different from those that can be gained through applying traditional methods. As a result, big data law approaches bring with them new questions surrounding their technical capabilities. We therefore assign the application of these data-driven approaches to legal problem-solving its own category, which we call "big data law."

Information scholars describe big data using four variables: volume, variety, velocity, and veracity. ${ }^{1}$ With regard to the volume of data, some contend that legal use cases employing data analytics do not deserve the label "big data" because, by comparison to other industries, such use cases do not involve zettabytes of data. Yet, as the analytical tools and approaches frequently overlap, application of the term "big data law" seems justified.

Many consider the term "big data law" to encompass research questions concerning both "technology for the law" and "law of technology." "Technology for the law" includes questions related to the use of analytics techniques to discover patterns in legal information and to derive new approaches to handling legal problems from the insights we gain. "The law of 


\section{Research handbook on big data law}

technology" includes legal, ethical, and policy questions arising from impacts of new data processing techniques and related technologies on individuals and societies (e.g., Should the law allow automatic decision-making for credit applications? What privacy regimes should we have in place? What are the ethical obligations of attorneys to use the latest technology to adequately represent their clients? What are the implications of this technology for the training of future lawyers?).

This research handbook primarily dwells on the "technology for the law" rather than "the law of technology." However, given that the two are often inseparable when reflecting on the impact of big data technologies, some chapters of this book devote considerable attention to the latter aspect as well. Clearly, though, all these questions are extremely consequential to the future of our legal system and, indeed, our society at large. Will our legal system make decisions based on real-world data-decisions that are more efficient, trustworthy, and fair-or will ours be a system that consolidates access, insight, and influence within the ranks of the privileged, and places increasingly powerful tools for social control in the hands of autocracies?

Big data analytics can yield insights into legal questions beyond what any fleet of human expert researchers can accomplish. However, these analyses are also subject to many of the same foibles as analyses by humans. In recent years, several books, and academic research and mainstream media articles, have increased awareness of the promise and pitfalls of big data analytics and automated decision-making systems in legal settings and beyond. ${ }^{2}$ It has become an important focus for legal and computer science researchers and policy makers alike who uncover, and propose solutions to mitigate, those weaknesses.

\section{WHY I DECIDED TO SERVE AS THE EDITOR OF THIS RESEARCH HANDBOOK}

I have devoted much of my professional life to the study of technology's impact on law and legal practice. Big data law has become a dominant phenomenon in the field, and researchers around the world discover ever more ways of leveraging big data analytics methods to find new insights about how the law works. This collection is a natural outgrowth of my long-standing interest in showcasing some of the great work emerging in this exciting area.

We have seen the impact of big data techniques and related technologies in various areas of law and legal practice for decades. First significant inroads were made 20 years ago in E-discovery, with the deployment of novel algorithms to improve search capabilities and save the expenses of human lawyers, displacing many entry-level jobs. Starting in the late 2000s, this trend spread to other areas of law and legal practice, with researchers as well as startups exploring and expanding upon numerous and diverse use cases, including judicial, IP, and contract analytics; prediction of legal outcomes from decision-makers across the legal spectrum, from patent examiners to Supreme Court justices; prediction techniques for law enforcement; jury selection; tax enforcement; litigation finance; and so on. As mentioned above, the work thus far provides a glimpse at a potentially exciting future for our legal system, where virtually any area of legal research and practice can be driven by data, helping to remove the obscurity that plagues many areas of the law today. Techniques currently applied to predicting judicial outcomes in high-stakes IP matters will, in the foreseeable future, come to your local landlordtenant dispute. 
At the time of this writing, the world is gripped by the COVID-19 pandemic, and many of the challenges we face underscore the immediacy of big data law. More than two million lives have been lost already, people are quarantined around the world, and there is a sense that the world may never look the same. Many of us have lost loved ones to this brutal illness, and we worry about what the future will hold. In the face of this widespread tragedy, members of the legal innovation community are rising to the challenge, using their talents and tools to help address the pandemic; indeed, there is an outpouring of related innovation around the globe, with many technologies described in this book being deployed in this effort. ${ }^{3}$ This pandemic like no other event in recent history-has highlighted the need for swift collaboration on local, regional, and global scales to gather and analyze data, and put insights into action. Fighting a vicious disease such as COVID-19 requires that we harness our best human effort, augmented by today's best technology. In this case, the immediate medical response - such as treating the illness; protecting the population; and developing tests, antivirals, and vaccinesis the first wave of action. Closely following are responses to a host of legal, procedural, and policy questions, to name just a few: when and how to implement social distancing, how to keep the legal system itself operational, how to provide government benefits, and when to reopen society.

While this book was more than two years in the making, the current confluence of events makes the topic more urgent than ever. I am thrilled that we have recruited some of the most accomplished researchers working on critical big data law projects to author and contribute their insights. I am also very pleased that this is a truly international effort, featuring viewpoints from around the world, including the U.S., Europe, China, and South America.

\section{BOOK STRUCTURE}

I arranged this book into 25 chapters featuring research projects representative of the field. As novel and important work is being done in both academic and commercial settings, I invited submissions from accomplished as well as rising scholars, along with industrial researchers working for companies that use big data law techniques in interesting new ways. As you approach this book, you may find the chapter overviews that follow this section helpful in determining where to start, and where you may wish to go next. Chapters provide examples of big data law research in various areas of law (e.g., criminal, tax, copyright, privacy, and administrative law). As mentioned, many contributing authors and their topics are international; thus, the subject of the research is at times a use case anchored in a particular legal system (e.g., anti-corruption in China, Brazilian Supreme Court case-load management). In contrast, other chapters delve into big data law approaches relevant across multiple practice areas: for example, machine learning within law, legal information retrieval, natural language processing, E-discovery, explainability of automated decision-making, certification of AI systems, and the relationship between generalizability and the division of labor between humans and machines in decision systems. Then, we have three chapters featuring industry project reports on using big data techniques: in contract analytics from the Israeli-U.S. startup LawGeex as well as the U.S. startup Klarity, and in client-lawyer matching from the Spanish startup elAbogado. 


\section{CHAPTER OVERVIEWS}

\section{Big Data Law Research Specific to Legal Subject Area}

\section{Criminal law}

Stanford Engineering's Sharad Goel and his co-authors write about Accuracy, Equity, and Jurisprudence of Criminal Risk Assessment, examining the statistical algorithms and risk assessment instruments (RAIs) that different jurisdictions and the U.S. federal government are using to help determine an arrestee's or an offender's risk of reoffending. The authors provide an in-depth analysis of the issues surrounding RAIs and also highlight how the law has, and should, respond to these issues.

Stephen Caines, a Residential Fellow at CodeX - The Stanford Center for Legal Informatics, examines the unique legal, ethical, and regulatory concerns around the ever-expanding use of facial recognition systems by law enforcement.

\section{Administrative law/AI use by government}

AI technology is transforming how government works. Stanford Law School Professors David Engstrom and Daniel Ho offer a unique and astute analysis of governance challenges raised by public sector adoption of AI, showing how these new algorithmic tools differ from prior public sector innovation.

\section{Copyright law}

Professor Daniel Seng from the National University of Singapore provides an overview of current research on big data analytics as applied to copyright law and fair use on the Internet. He bases his analysis on data collected by content providers and Internet intermediaries on the use of digital content online, and offers unique insights into the workings of copyright-based industries.

\section{Privacy law and terms of use}

Przemysław Pałka from Yale Law School and Professor Marco Lippi from the University of Modena survey the research technologies that help consumers analyze website terms of service and privacy policies.

\section{Tax law}

Professor Benjamin Alarie from the University of Toronto and his co-authors discuss the use of big data analytics and machine learning to gain insights in the field of tax law. The authors not only introduce ways to improve the administration and content of tax law and policy, but also ways taxpayers can use these technologies to better understand applicable law.

\section{Anti-corruption}

Ran Wang, Associate Professor at Tianjin University of China, introduces us to the world of big data analytics-driven anti-corruption efforts in China. She examines the Chinese legal framework surrounding corruption-fighting, as well as legal challenges launched against some of these efforts, based on protection of personal information, the quality and reliability of data and algorithms, and due process. 


\section{Big Data Law Research Applicable Across Legal Subject Areas}

\section{Machine learning and the law}

Professor Harry Surden from the University of Colorado Law School in Boulder addresses the growing use of machine learning within the legal domain, providing us with a unique overview of both the new capabilities that machine-learning brings to legal analysis, as well as its limits and surrounding social controversies.

Ashkon Farhangi and Ajay Sohmshetty present a novel machine learning approach to U.S. Supreme Court prediction, combining structured data with raw textual court transcripts to improve predictive performance.

\section{Legal information retrieval}

Legal information retrieval is one of the technology pillars enabling big data law research and applications. Dr. Ashraf Bah Rabiou provides us with an excellent state-of-the-art overview on the workings of legal information retrieval.

\section{LexNLP: Natural language processing and information extraction for legal and regulatory texts}

Professor Daniel Katz from Chicago-Kent College of Law, Michael Bommarito, and Eric Detterman from the legal analytics company LexPredict (now part of Elevate) introduce us to LexNLP, an open source Python package focused on natural language processing and machine learning for legal and regulatory text. LexNLP is designed for use in both academic research and industrial applications.

\section{Quantitative legal research in Germany}

Dirk Hartung provides us with a fascinating deep dive into the varied challenges facing quantitative legal research in Germany. Hartung makes a strong case for an interdisciplinary approach that is also open to doctrinal legal scholars.

\section{E-discovery}

Professor J.C. Scholtes and Professor H.J. van den Herik from Maastricht University in the Netherlands explain that E-discovery demands more from search, analytics, and machine learning than other business applications. They provide an excellent overview of the history of E-discovery, from 1985 to present, and then discuss possible future applications of big data analytics in this area.

\section{Generalizability}

In their chapter, Generalizability: Machine Learning and Humans-in-the-loop, John Nay, CEO of Skopos Labs, and Professor Katherine J. Strandburg from NYU Law School explore the relationship between generalizability and the division of labor between humans and machines in decision systems. They discuss design stages for integration of machine and human decision-making and underscore the importance of these stages to a decision system's ultimate ability to generalize to real-world cases. 
Big data law research and court efficiency

Ricardo Vieira de Carvalho Fernandes, Chief Legal AI Researcher at Neoway, and his co-authors Danilo Barros Mendes, Gustavo Henrique T.A. Carvalho, and Hugo Honda Ferreira introduce us to the VICTOR project, an innovative machine learning project carried out by Supremo Tribunal Federal, Brazil's Supreme Federal Court. This project aids judicial decision-making by applying artificial intelligence, in the form of document classification, to screen lawsuits.

\section{Explainable artificial intelligence}

Professor Mary-Anne Williams from the University of Technology in Sydney explains that, although AI is outperforming human experts in an ever-growing array of recognition, prediction, and decision-making tasks, it is unable to generate causal models and explanations for its perceptions, decisions and recommendations, and actions. She astutely shows that explainable AI (XAI) can address some of the more serious AI risks, to build the trust needed for widespread adoption.

Dr. Bernhard Waltl, a data scientist at the BMW Group in Munich, also provides an in-depth analysis of current issues surrounding explainability and transparency of machine learning in automated decision-making systems. He focuses on various aspects of transparency, discussing methods for increased understanding of AI system behavior.

\section{Certifying artificial intelligence systems}

Professor Florian Möslein from the Philipps-University Marburg and Professor Roberto V. Zicari from Goethe University Frankfurt in Germany introduce us to different certification mechanisms for AI systems in order to promote trust and compliance, and discuss the questions surrounding their regulatory design.

\section{Rules, cases, and arguments in artificial intelligence and law}

Heng Zheng and Professor Bart Verheij from the University of Groningen in the Netherlands present three styles of legal reasoning as they have been studied in the field of artificial intelligence and law: rule-, case-, and argument-based reasoning. These are illustrated in the context of Dutch tort law, offering a unique guide to understanding intricacies of legal reasoning, and challenges associated with teaching legal reasoning to computers.

\section{Big data litigation and lawyers' ethical responsibilities}

Well-known Silicon Valley IP litigator James Yoon, of the law firm Wilson Sonsini Goodrich \& Rosati, addresses ethical responsibilities of litigators to incorporate new technologies, focusing on the ways AI and data analytics are transforming how lawyers try cases and collaborate with clients.

\section{Big data and assessing the quality of legal services}

In his lucid and persuasive chapter, Evaluating Legal Services: The Need for a Quality Movement and Standard Measures of Quality and Value, Professor Daniel Linna from Northwestern Pritzker School of Law and McCormick School of Engineering goes beyond making the case for a quality movement, analyzing numerous key initiatives contributing to the development of quality and value metrics for the legal services industry. 


\section{Legal aspects of machine learning training datasets for AI systems}

In his chapter, Machine Learning and EU Data-Sharing Practices, Mauritz Kop from the Netherlands undertakes an analysis of the legal issues surrounding the ownership of datasets used for machine learning applications as well as related data protection issues.

\section{Big Data Law Project Reports from Industry}

\section{Big data contract analytics}

Dr. Shlomit Labin, VP of Research, and Uri Segal, Data Scientist, at the U.S.-Israeli legal tech startup LawGeex, provide an in-depth look at the company's use of natural language processing to automate contract review. They explain the distinct characteristics that differentiate legal language from natural language, and ways these characteristics inform the design of the AI solution for contract review. Special attention is given to metrics for evaluating classification results and the issue of inconsistencies among annotators. The latter is a common problem in the legal domain and beyond, affecting both the training and evaluation of the classifier solution.

Klarity co-founders Andrew Antos, CEO, and Nischal Nadhamuni, CTO, focus on the mining, analysis, and use of data from contracts. In their chapter, Practical Guide to Artificial Intelligence and Contract Review, they provide a unique overview of the evolution of natural language processing in the context of contract intelligence and its practical applications.

\section{Big data attorney - client match-making}

In their chapter, Legal Marketplaces Using Machine Learning Techniques, Verónica Sorin and Martí Manent, from the Spanish-language online lawyer marketplace elAbogado, demonstrate a system they developed that combines data and state-of-the-art artificial intelligence techniques to select leads and connect clients with the right lawyers.

While this collection provides a unique survey of big data law research that is currently undertaken in academia and industry, it is not comprehensive; many other worthwhile efforts in this growing field deserve attention. But this selection will provide you with a solid overview of work from some of the field's leading thinkers. I hope that this volume will inspire other research and application to advance the potential that big data law has to improve law, legal systems, and society. The need could not be timelier, nor more urgent.

\section{NOTES}

1. See, e.g., Amir Gandomi \& Murtaza Haider, Beyond the hype: Big data concepts, methods, and analytics, 35 InT'L J. INFo. MGmT. 137 (2015); Wikipedia defines these characteristics as follows: "Volume: The quantity of generated and stored data. The size of the data determines the value and potential insight, and whether it can be considered big data or not. Variety: The type and nature of the data. This helps people who analyze it to effectively use the resulting insight. Big data draws from text, images, audio, video; plus, it completes missing pieces through data fusion. Velocity: The speed at which the data is generated and processed to meet the demands and challenges that lie in the path of growth and development. Big data is often available in real-time. Compared to small data, big data are produced more continually. Two kinds of velocity related to big data are the frequency of generation and the frequency of handling, recording, and publishing. Veracity: It is the extended definition for big data, which refers to the data quality and the data value. The data quality of cap- 
tured data can vary greatly, affecting the accurate analysis"; see, Big data, WIKIPEDIA, available at https://en.wikipedia.org/wiki/Big_data (last visited Sept. 5, 2020).

2. E.g., Steffen Mau, The Metric Society: On the Quantification of the Social (2019) (highlighting the problems that can arise when societies rely too much on statistics, suggesting that metrics have in fact become a form of social conditioning).

3. A few among numerous examples: the company Skopos Labs is tracking federal U.S. policy-making addressing COVID-19, Skopos LABS, COVID PoliCy TRACKER, https://coronavirus.skoposlabs .com/?fbclid=IwAR1GwLAiy-is05KdeOm3Mfux-eojA3qAX3PV5971wh10h39EeM5vFhqzxuY (last visited Sept. 5, 2020); German legal tech innovators created a platform to help those affected by the pandemic access Germany's government support programs, MACHER HILFE, www.macher -hilfe.de (last visited Sept. 5, 2020); Stanford Law School launched a COVID-19 memo database, covering more than 9,000 law firm memos on COVID-19, Stephanie Ashe, Stanford Law School Launches COVID-19 Memo Database in Collaboration with Cornerstone Research, SLS News \& ANNOUNCEMENTs (Apr. 15, 2020), https://law.stanford.edu/press/stanford-law-school-launches -covid-19-memo-database-in-collaboration-with-cornerstone-research/ (last visited Sept. 5, 2020); the CoronAtlas project, conducted by CodeX - The Stanford Center for Legal Informatics maps regulatory responses in the U.S. down to the county level, CoRONATLAS, COVID-19 MAP, https://coronatlas.com/map (last visited Sept. 5, 2020); an Oxford University project is tracking policy responses to COVID-19, BlaVATNIK SCHOOL OF GovernMENT \& UNIVERSiTy OF OXFORD, CORONAVIRUs GOVERNMENT RESPONSE TRACKeR, https://www.bsg.ox.ac.uk/research/research -projects/coronavirus-government-response-tracker (last visited Sept. 5, 2020); similarly, the Future Law Institute in the UK is currently focused on creating a database for global COVID-19 policy responses, Future LaW Institute, https://futurelaw.io/ (last visited Sept. 5, 2020).

\section{REFERENCES}

Ashe, Stephanie (2015), Stanford Law School Launches COVID-19 Memo Database in Collaboration with Cornerstone Research, SLS News \& Announcements (Apr. 15, 2020), https://law.stanford .edu/press/stanford-law-school-launches-covid-19-memo-database-in-collaboration-with-cornerstone -research/.

Big data, WiKIPEDIA, https://en.wikipedia.org/wiki/Big_data.

Blavatnik School of Government \& University OF OXford, Coronavirus GovernMENT Response TRACKER, https://www.bsg.ox.ac.uk/research/research-projects/coronavirus-government-response-tr acker.

CORONATLAS, COVID-19 MAP, https://coronatlas.com/map.

Future Law Institute, https://futurelaw.io/.

Gandomi, Amir \& M. Haider (2015), Beyond the hype: Big data concepts, methods, and analytics, 35 INT'L J. INFo. Mgmt. 137-144.

MaChER Hilfe, www.macher-hilfe.de.

Mau, Steffen (2019), The Metric Society: On the Quantification of The Social.

Skopos Labs, COVID Policy Tracker, https://coronavirus.skoposlabs.com/?fbclid=IwAR1GwLAiy -is05KdeOm3Mfux-eojA3qAX3PV597lwhl0h39EeM5vFhqzxuY. 